\title{
Ead: a ferramenta fórum do espaço virtual de aprendizagem (EVA) e a constituição da autoria
}

Conceição Aparecida Kindermann ${ }^{1}$

Este artigo tem como objetivo analisar de que forma o EVA (Espaço Virtual de Aprendizagem) proporciona aos estudantes de graduação constituírem-se sujeitos autor, levando-se em consideração as especificidades do ciberespaço e se esse espaço contribui para o desenvolvimento de práticas autorais. Consideram-se, então, o ciberespaço e a educação a distância. A plataforma analisada é o Espaço Virtual de Aprendizagem - EVA - da Universidade do Sul de Santa Catarina. O corpo teórico fundamenta-se especialmente em Pêcheux, Orlandi e Furlanetto. Quanto à metodologia, segue os dispositivos teóricometodológicos da Análise de Discurso. Os principais resultados, em relação à constituição do sujeito, apontam para a) a constituição do sujeito autor em níveis diferenciados; e b) a autoria textualizada sob diversas ancoragens.

Palavras-chave: Constituição do sujeito-autor. Níveis de autoria. Educação a distância.

\section{Ead: the virtual learning space (VLS) forum tool and the creation of authorship}

This article aims to analyze how the VLA (Virtual Learning Space) enables graduate students to be subject authors, taking into account the specificities of cyberspace and whether this space contributes to the development of copyright practices. The cyberspace and the distance education are then considered. The analyzed platform is the Virtual Learning Space - VLS from the Universidade do Sul de Santa Catarina. The theoretical framework is especially based in Pêcheux, Orlandi and Furlanetto. Regarding the methodology, this research follows the theoretical and methodological Discourse Analysis principles. The main results regarding the subject constitution, point out to a) the constitution of the subject author in different levels; and b) the textualized authorship under various anchorages.

\footnotetext{
${ }^{1}$ Doutora pela Universidade do Sul de Santa Catarina - UNISUL. Professora nos cursos de graduação e licenciatura nessa universidade. E-mail: cida.kindermann@unisul.br
}

Criar Educação, Criciúma, v. 8, n¹, jan/jul 2019.- PPGE - UNESC 
Keywords: Constitution of the author-subject. Levels of authorship. Distance Learning Education.

\section{INTRODUÇÃO}

Este trabalho parte da linguagem como forma de constituição do sujeito, que lhe permite compreender o mundo e, sobretudo, agir. Trata da linguagem como prática social, como mediação necessária entre o homem e sua realidade natural e/ou social - com foco na constituição da autoria.

Por conseguinte, por tratar da linguagem em situação real de uso, visa contribuir com o desenvolvimento de práticas sociais a partir da escola, como instância privilegiada em que o sujeito pode se constituir autor. A cena a ser analisada não se centra mais em uma sala de aula, situada no tempo e espaço, mas em um espaço virtual de aprendizagem, o EVA. Assim, esta pesquisa tem como foco a escrita a partir do Ensino a Distância - EaD.

A Educação a Distância $(\mathrm{EaD})$ surge como estratégia para atender às exigências de mercado, ou atender pessoas que não tiveram acesso ao sistema presencial de ensino, primeiramente. Com os avanços tanto na área da educação como na área tecnológica tornaram possíveis novas metodologias centradas em diversas mídias, impulsionando cada vez mais a EaD. Tais tecnologias permitiram reduzir as distâncias entre professor-estudante, estudante-estudante.

Neste estudo, trabalha-se com a sala virtual (Espaço Virtual de Aprendizagem) da UNISUL - Universidade do Sul de Santa Catarina. É um espaço colaborativo entre aluno e professor - EVA - em que eventos/práticas de linguagem acontecem, de modo a propiciar a escrita (autoria), desvinculando-se do espaço físico da Escola (a cultura do papel) para um novo espaço - o virtual.

É com esta premissa - o ciberespaço - que esta pesquisa se instaura, que se pressupõe seja uma instância que favoreça ao sujeito a prática da autoria.

É objetivo da pesquisa analisar de que forma o EVA proporciona aos estudantes de graduação constituírem-se sujeitos autor, levando-se em consideração as especificidades do ciberespaço e se realmente esse espaço contribui para o 
desenvolvimento de práticas autorais. Para alcançar esse objetivo, são adotados os dispositivos teórico-metodológicos da Análise de Discurso de linha francesa.

Fazem parte do corpus desta pesquisa as produções de 9 alunos, da disciplina de Leitura e Produção Textual (60 horas) de um curso de licenciatura em Pedagogia a distância, que se desenvolve no EVA (Espaço Virtual de Aprendizagem) da Unisul - Universidade do Sul de Santa Catarina. Essas produções dos alunos foram postadas no fórum, uma das ferramentas desse ambiente virtual de aprendizagem. O fórum analisado foi "Que tal desligar a TV?". Os alunos deveriam fazer uma leitura prévia de um texto cujo título é o mesmo do fórum proposto. Neste artigo, são selecionadas a produção de 4 alunos, em virtude do limite de caracteres.

Nas seções que seguem, são apresentadas: a) o cenário da Análise de Discurso; b) função-autor; c) heterogeneidade do discurso; d) sujeito posição-autor, apresentando a análise; e c) considerações finais.

\section{EXPONDO O CENÁRIO DA ANÁLISE DE DISCURSO}

A Análise de Discurso (AD) surge na França, no final da década de 60, tendo como principal articulador Michel Pêcheux. É com esse autor que essa área do conhecimento ganha corpo. A Análise de Discurso abre um novo campo de estudos, traz uma nova concepção de língua, de historicidade e de sujeito, deixados à margem até então, dado que a língua, objeto de estudo na conjuntura estruturalista, não é afetada pela exterioridade, geradora de irregularidades.

$A A D$ se situa no entremeio de três regiões do conhecimento: Linguística (desloca-se da concepção dicotômica língua/fala para língua/discurso; a língua não apenas como estrutura, mas também como acontecimento, sujeita a falhas), Marxismo (teoria da Ideologia) e Psicanálise (a noção do inconsciente, o sujeito descentrado, clivado). É no entremeio dessas três áreas do conhecimento que se situa a Análise de discurso.

Ao trabalhar na confluência dessas áreas de conhecimento, a $A D$ toma como objeto de estudo o discurso, concebido como efeito de sentido entre locutores. É na língua que se materializam o ideológico, o histórico, o social. A língua não pode 
ser mais entendida como uma abstração, mas como prática de linguagem; vista como estrutura, mas não desvinculada do acontecimento.

A relação entre linguagem, pensamento e mundo não é direta, tampouco se faz termo a termo. Não é possível pensar na transparência dos sentidos, como se os significados das palavras estivessem sempre "já lá". O sentido se constitui no momento da discursivização, no momento da enunciação, condicionado à posição assumida pelo sujeito (posição-sujeito), afetado pela ideologia.

O discurso materializa-se em enunciados. Para Foucault (2002, p.135), o discurso pode ser definido como:

[...] um conjunto de enunciados, na medida em que se apoiem na mesma formação discursiva; ele não forma uma unidade retórica ou formal, indefinidamente repetível e cujo aparecimento ou utilização poderíamos assinalar (e explicar, se for o caso) na história; é constituído de um número de enunciados para os quais podemos definir um conjunto de condições de existência.

O enunciado pode ser compreendido, em sua singularidade, como acontecimento discursivo; está ligado a um ato de um sujeito a uma posição-sujeito, a um gesto de escrita ou à articulação de uma palavra; embora seja único, está aberto à repetição, porém, uma vez que está ligado a situações de usos, a posições ocupadas pelo sujeito, cada enunciado será sempre um acontecimento.

A posição-sujeito é uma noção teórica que, no processo discursivo, representa o lugar no qual os sujeitos estão inscritos na estrutura de uma formação social. Essa posição-sujeito espelha a forma-sujeito. Em tese, para cada formação discursiva, há uma forma-sujeito e, conforme essa forma-sujeito, o sujeito, ao enunciar, identifica-se com essa forma-sujeito e, na posição-sujeito, enuncia.

A partir do enunciado, Foucault (2002, p. 43) teoriza a noção de formação discursiva:

No caso em que se puder descrever, entre um certo número de enunciados, semelhante sistema de dispersão, e no caso em que entre os objetos, os tipos de enunciação, os conceitos, as escolhas temáticas, se puder definir uma regularidade (uma ordem, correlações, posições e funcionamentos, transformações), diremos, por convenção, que se trata de uma formação discursiva. 
Pêcheux traz para a AD esse conceito de formação discursiva de Foucault; investe nos aspectos linguísticos e insere a noção dentro das proposições althusserianas.

A formação discursiva, para esse autor, é considerada "aquilo que, numa formação ideológica dada, isto é, a partir de uma posição dada, determinada pelo estado da luta de classes, determina o que pode e deve ser dito (articulado sob a forma de uma arenga, de um sermão, de um panfleto, de uma exposição, de um programa, etc.)". (PÊCHEUX, 1997, p. 160).

Em um primeiro momento, a noção formulada por Pêcheux de formação discursiva poderia ser compreendida como um bloco homogêneo, com regularidades estabelecidas, mas se sabe que os sujeitos, em suas práticas discursivas, não se submetem inteiramente às determinações de uma formação discursiva, há atravessamentos e suas fronteiras são movediças. Poderíamos falar em vista disso em "mau sujeito" como aquele que se afasta de determinada formação discursiva em que se inscreve ou em que, aparentemente, estaria inscrito.

Destaca-se que uma formação discursiva comporta uma forma-sujeito historicamente determinada e que regula o que pode ser dito ou não na tomada de posição pelo sujeito (posição-sujeito). A maneira como a posição-sujeito se relaciona com essa forma-sujeito aponta para a não homogeneidade da FD e, por consequência, também do discurso, porquanto, uma forma-sujeito comporta diferentes posições-sujeito.

Essa interpelação do sujeito pela ideologia, que cria um sujeito assujeitado, com base em Althusser, é revista por Pêcheux (1997) no anexo III de Semântica e discurso. É do ponto de vista da psicanálise que Pêcheux propõe uma explicação para a resistência do sujeito dominado pela ideologia. Essa resistência do sujeito aparece no momento do chiste, do ato falho, do equívoco.

Outra noção, a de interdiscurso, vem dominar a construção teórica da AD. O interdiscurso, para Pêcheux (1997, p. 162), é o "[...] "todo complexo com dominante" das formações discursivas, esclarecendo que também ele é submetido à lei de desigualdade-contradição-subordinação que, como dissemos, caracteriza o complexo das formações ideológicas". 
Não se pode pensar que não haja deslizamentos nas formulações feitas pelos sujeitos ao assumir determinadas posições. O sujeito pode ser "um mau sujeito", aquele que não segue as regularidades de sua posição em determinado contexto.

Para explicar essa "liberdade aparente" do sujeito, fonte do seu dizer, Pêcheux (1997), a partir de Freud, formula a noção dos "dois esquecimentos" inerentes ao discurso; ilusão necessária ao sujeito. O esquecimento " $n$ 2 " é visível na enunciação, está no nível do "sistema pré-consciente-consciente": o sujeito-falante tem a ilusão de selecionar, rejeitar, organizar, aquilo que pode dizer ou não; imagina, também, que o que está dizendo é a expressão transparente da realidade. Já no esquecimento "n 1", no nível do "sistema inconsciente", o sujeito-falante, ao enunciar, tem a ilusão de ser origem de seu discurso, sente-se dono de seu dizer. Resulta da forma como o sujeito é afetado pela ideologia.

A Análise de discurso, pela sua abrangência teórica, dá conta dos processos tanto de escrita como de leitura, por tratar da língua em sua materialidade, opacidade, sujeita a equívocos, a falhas, marcada pela historicidade e pela ideologia. Só há língua porque existem sujeitos que a falam. A língua é condição de possibilidade do discurso.

\section{FUNÇÃO-AUTOR}

Falar de autoria é falar do próprio sujeito. A autoria está relacionada ao sujeito, à sua posição ocupada em um determinado acontecimento discursivo; é atividade de linguagem em uso. Ao se defrontar com situações em que tenha que usar a linguagem, o sujeito se coloca na posição autor, uma vez que produz uma unidade textual.

Para Foucault (1996, p. 26, 28), o autor é perspectivado como “[...] princípio de agrupamento do discurso, como unidade e origem de suas significações, como foco de sua coerência. [...] O autor é aquele que dá à inquietante linguagem da ficção suas unidades, seus nós de coerência, sua inserção no real”. Mas há muitos textos que circulam no dia a dia que não apresentam a marca da autoria, são gêneros discursivos que pela sua própria lógica de circulação nas esferas sociais, não 
prescindem da "assinatura do autor", como receitas culinárias, manual de produtos, bulas de remédios etc.

Na obra O que é um autor? de Foucault (1997), há um deslocamento do sujeito empírico/obra para texto/autor. O sujeito empírico, antes, se imortalizava em suas obras, e essas obras também o imortalizavam.

O texto aponta para o autor "que lhe é exterior e anterior, pelo menos em aparência". (FOUCAULT, 1997, p. 34). Foucault fala da escrita como prática desconectada do sujeito empírico; diante disso, não importaria quem escreve, mas o texto em si. Mas, nas sociedades atuais, há os "direitos autorais", principalmente para aqueles que já se consagraram autores, há uma relação do nome do autor, sujeito empírico, com sua obra.

A Análise de Discurso não trata exatamente da função-autor, mas a partir da noção de sujeito, posição-sujeito, pode-se relacionar a função-autor, uma função desempenhada pela posição-sujeito. A autoria está relacionada, pois, a uma posiçãosujeito, a ser preenchida a cada acontecimento.

A proposta de Foucault foi assumida parcialmente, no contexto da Análise do Discurso. A noção de função-autor de Foucault é, portanto, reformulada por Orlandi, no contexto da AD, ao afirmar que a unidade textual deriva do princípio de autoria. É reelaborada no sentido de que a autoria, para Foucault, é restrita, apenas a textos/obras já institucionalizadas; exemplares quaisquer de textos que circulam em outros meios não teriam um "autor", mas um escritor/redator etc. Também, para Foucault, o nome do autor limita a pluralidade de sentidos, o que não se percebe em Orlandi.

É importante destacar que a constituição da autoria está em relação com produção e circulação de textos ligados a situações reais de uso. O Espaço Virtual de Aprendizagem (EVA) é uma ferramenta que pode oportunizar aos alunos essa prática; neste ambiente, todos os alunos têm acesso à produção de cada um.

Esta pesquisa parte das noções de autoria propostas por Furlanetto e Orlandi. A concepção de autoria aqui, conseguintemente, relaciona-se à produção de linguagem, a eventos enunciativos que estão disponíveis no EVA.

\section{HETEROGENEIDADE DO DISCURSO}

Criar Educação, Criciúma, v. 8, nº, jan/jul 2019.- PPGE - UNESC 
O discurso é fundamentalmente heterogêneo. Essa noção de heterogeneidade não foi proposta nos estudos iniciais de Pêcheux. Foi a partir da reformulação da noção de formação discursiva, caracterizada, agora, por atravessamentos, por deslizamentos, que a noção de discurso também sofreu revisão. No interior de uma mesma formação discursiva coexistem discursos oriundos de outras formações discursivas. Não há fronteiras, os limites são movediços conseguintemente o discurso, por filiar-se a uma formação discursiva, não é um bloco homogêneo, uma vez que reproduz os conflitos, contradições dessa formação discursiva da qual provém.

Authier-Revuz (1990) se vale de uma abordagem que vai contra a noção de sujeito como fonte de seu dizer. Para isso, apoia-se, de um lado, em trabalhos que tomam o discurso como produto do interdiscurso, ou o dialogismo de Bakhtin e, por outro lado, na abordagem do sujeito e de sua relação com a linguagem permitida por Freud e sua releitura por Lacan.

A autora propõe uma descrição da heterogeneidade mostrada; como formas linguísticas podem representar diferentes modos de negociação do sujeito falante com a heterogeneidade constitutiva de seu discurso. Isto é, como o sujeito se porta em relação à produção de seu discurso, que marcas de sua singularidade estão no seu discurso, para criar o efeito de "propriedade" e outras marcas do discurso do outro, nesse caso, mostrada.

A heterogeneidade pode ser: a) mostrada: há pistas recuperáveis na superfície do discurso. Pode ser, ainda, marcada e não-marcada. Marcada: palavras entre aspas, em itálico, discurso direto etc. Não-marcada: ironia, discurso indireto livre, pastiche etc. e b) constitutiva: não está na organização linear do discurso, mas no interdiscurso, por isso não é apreensível no nível do dito. (AUTHIER-REVUZ, 1990).

A heterogeneidade marcada é apreensível no fio do discurso - vê-se o "outro" -, remete a um exterior que não está no interior do fio do discurso. Essa heterogeneidade é necessária para mostrar que o que se está falando não é do "eu", mas provém de um outro, conforme o participante faz ao trazer nomes de autores e anos das publicações. 
Essas formas marcadas criam o efeito de sentido de que o enunciador é capaz de se colocar distante de sua língua e de seu discurso, numa posição de observador, no caso de retificação, de reserva etc.

\section{SUJEITO: POSIÇÃO-AUTOR}

A noção de sujeito recobre não um ser no mundo, mas um lugar, uma posição discursiva. A autoria está relacionada a uma posição-sujeito, uma posição a ser ocupada a cada acontecimento discursivo pelo sujeito. Faz-se necessário dizer que a enunciação sob a perspectiva discursiva, levando em consideração os pressupostos da AD, está em relação com o acontecimento. E a cada acontecimento, pressupõe-se autoria/autor.

O autor dá ao texto uma certa forma, estilo, em função de um leitor imaginado no momento da organização textual. Discursivamente, a autoria é uma função do sujeito como também o efeito-leitor. É na função-autor que o sujeito se organiza como unidade, que tem a ilusão de ser a fonte de seu dizer, como sujeito (forma-sujeito); a relação com o discurso é de dispersão. A singularização do sujeito ocorre no momento em que se constitui autor, princípio organizador do discurso.

O sujeito reagrupa em seu discurso o já-dito, o dizível (de acordo com a formação discursiva em questão, aquilo que pode ser dito), o historicizável e, para isso, utiliza-se de elementos da língua, numa estrutura linguística, com coerência, com fecho, capaz de ser interpretável. Esse fecho é apenas um efeito de acabamento do texto, que dá ao sujeito a ilusão de sua unidade, constituindo-se autor.

A partir da análise das produções dos sujeitos-alunos, aqui ocupando essa posição, por tratar de um ambiente acadêmico, o que não implica que esses alunos possam se movimentar por outras posições, dado que a materialidade do texto proporciona essa dinamicidade, busca-se "escutar" as marcas de autoria.

Parte-se já do pressuposto de que em todas as materialidades aqui analisadas exista autoria, por entender que a autoria está para todos os textos, assim como o sujeito está para o discurso. O que se objetiva é analisar os patamares/níveis de autoria. 
Para atingir os objetivos propostos nesta pesquisa, foi elaborado um quadro, para servir de parâmetros para a análise, conforme segue abaixo.

Quadro 1 - Adaptação do jogo autoral proposto por Furlanetto (2008) e Orlandi (1996).

\begin{tabular}{|c|c|c|c|}
\hline Nív & \multicolumn{2}{|c|}{ Memória discursiva } & Produção subjetiva \\
\hline & Querer-dizer & $\begin{array}{l}\text { Iterar (paráfrase, } \\
\text { repetição) }\end{array}$ & $\begin{array}{c}\text { Alterar } \\
\text { (polissemia, dispersão) }\end{array}$ \\
\hline 1 & $\begin{array}{l}\text { Repetição empírica - } \\
\text { efeito papagaio. }\end{array}$ & $\begin{array}{l}\text { Pouco controle dos } \\
\text { mecanismos textuais }\end{array}$ & Iterar para alterar \\
\hline 2 & $\begin{array}{l}\text { Repetição formal - } \\
\text { um outro modo de } \\
\text { dizer o mesmo }\end{array}$ & $\begin{array}{l}\text { Articulação dos elementos } \\
\text { textuais } \\
\text { Controle dos mecanismos } \\
\text { textuais }\end{array}$ & Alteração controlada \\
\hline 3 & $\begin{array}{l}\text { Organização do texto } \\
\text { (critérios de coesão e } \\
\text { coerência) }\end{array}$ & $\begin{array}{l}\text { Controle dos mecanismos } \\
\text { discursivos. } \\
\text { Heterogeneidade marcada. }\end{array}$ & Historicização do sentido \\
\hline
\end{tabular}

Fonte: autora

A análise tem como perspectiva, então, o autor "[...] não entendido, é claro, como indivíduo falante que pronunciou ou escreveu um texto, mas o autor como princípio de agrupamento do discurso, como unidade e origem de suas significações, como foco de sua coerência (FOUCAULT, 2002, p. 25)", reformulado por Orlandi (1988), função assumida pelo "eu" enquanto produtor de linguagem e, ainda, o autor como lugar em que se constrói a unidade do sujeito.

Os alunos participantes desta pesquisa são nomeados como participantes $(P)$, seguido de uma numeração.

\subsection{SUJEITO P1}

$\mathrm{O}$ sujeito enunciador $\mathrm{P} 1$, na posição-aluno, produz seus textos, retorna para o seu dizer essa memória que fornece os implícitos (a possibilidade de leitura da materialidade de seu texto), mas ao mesmo tempo, como é um acontecimento discursivo que se instaura, "desregula" a rede de implícitos e cria uma outra regularização. 
Isso posto, não se pode considerar a memória como "uma esfera plena, cujas bordas seriam transcendentais históricos e cujo conteúdo seria um sentido homogêneo, acumulando ao modo de um reservatório (PÊCHEUX, 2010, p. 56)". Pelo contrário, a memória deve ser entendida como um espaço de deslocamentos, de conflitos de regularizações, um espaço de "contra-discursos". Por isso que o formulável pelo sujeito, por mais que esteja no nível do repetível, instaura-se em um novo acontecimento.

Na materialidade do texto do sujeito em análise, podem ser observados os mecanismos de coesão, de acordo com os elementos de que a língua dispõe. Seguem algumas sequências abaixo, em negrito, entre outras que podem ser visualizadas no anexo B:

SQ 1 "concordo com sua posição no que tange quanto a TV [...]"

SQ 2 "Você foi a única a mencionar esta ação concreta [...]"

SQ $3[\ldots]$ é fruto de nossa responsabilidade/passividade [...] Temos nossa parcela de culpa nessa relação bilateral [...].

Esse sujeito, ao trazer o exterior para o interior de seu texto, pelo viés da heterogeneidade mostrada, sinaliza um movimento de controle de seu dizer, o fio do discurso (intradiscurso) se organiza em parágrafos e aparecem articulados, para constituir os textos. Posiciona-se de forma a controlar a dispersão, a deriva devido à equivocidade da língua.

Na sequência (4) "[...] Sim, a TV nossa de cada dia e de todos os dias... [...]", pela aproximação que faz entre "o pão nosso de cada dia" (discurso religioso) e "a TV nossa de cada dia" (discurso da mídia), denota conhecimento do funcionamento linguístico, aponta para um deslizamento de sentido. É esse "não controle" do sentido que denota o efeito de autoria. Ao trazer as palavras já-ditas, advindas de outras formações discursivas, como a associação "TV nossa de cada dia" com "pão nosso de cada dia”, são atravessadas pelo esquecimento, para que o novo se instaure no texto produzido.

Em seus textos, há o efeito de acabamento, ou deixando para o leitor a tarefa de dar o fecho para o texto, conforme pode ser visto na sequência: "[...] Eu sou uma dessas... Tenho filho pequeno e meu dia é uma loucura, então, quando há um 
tempinho de ver um programa que gosto, uno as duas coisas, embora saiba que não é saudável... [...]".

Ao enunciar, o sujeito P1 desdobra-se: a) como enunciador que declara algo, que diz; e b) como metaenunciador, ao inserir-se como o outro que fala sobre o seu dizer. Esse sujeito une diversas vozes em seu dizer, marcadas, anônimas, essas advindas do interdiscurso e tem conhecimento das "costuras" a serem feitas para que na linearidade discursiva não haja rupturas.

Por conseguinte, a partir da memória discursiva, o sujeito ao estabelecer uma relação com essa exterioridade, remete ao mesmo tempo esse já dito (o "iterar"), para o interior de seu texto, em um movimento de "conflitos de regularização", instaurar o novo, um novo acontecimento discursivo.

\subsection{SUJEITO P2}

O lugar social que o sujeito empírico ocupa, nesta pesquisa é de aluno. Esse lugar é que determina a posição-aluno. Dessa posição, o que o sujeito produz está em relação com o que pode ou deve dizer. No entanto, pode haver atravessamentos, deslizes, o que o próprio Pêcheux reconhece ao considerar que pode haver o "mau-sujeito", conforme já explicitado antes.

Ao trazer famílias parafrásticas de formações discursivas (FD) diferentes para seu discurso, o sujeito as insere em uma nova matriz de sentido, instaurando o novo; o sujeito enunciador mostra-se capaz de mover-se nessas formações discursivas, uma vez que pode identificar-se com elas, entretanto sem ocupar uma posição nessas formações discursivas, já que a sua inscrição é na FD da academia.

Quantos aos critérios de textualidade, utiliza recursos linguísticos que garantem a coesão e a coerência. Há recursos na linearidade de seu texto, como o uso da forma interrogativa: "[...] A grande questão encontra-se no processo de desintoxicação, que no caso das drogas, com persistência, é possível, e no caso da tv?" que aponta para um efeito de sentido diferente do que seria um fecho para um texto, como se trata de um assunto polêmico, o sujeito enunciador também polemiza esse acabamento, deixando a dúvida transparecer. Mesmo que seja um fecho 
singular, é um fecho. Logo, cumpre com uma das características do texto: ter começo meio e fim, também um critério que se atribui à função-autor.

O sujeito enunciador ao formular/produzir suas materialidades discursivas instaura um gesto de interpretação, o que permite a historicização do sentido, do texto. E, em face disso, constitui-se autor.

\subsection{SUJEITO P3}

Três das participações do sujeito P3 foram cópias de sites da internet, apenas em um comentário coloca-se como produtor de discursividade.

Uma palavra faz sentido porque esse sentido já existe em potencialidade no interdiscurso. O sujeito mobiliza esse sempre-já-lá das palavras, que sustenta o seu dizer, processo esse esquecido pelo sujeito (esquecimento ํㅜㅅ), e inscreve o seu dizer no fio do discurso (esquecimento no2) que emerge em um acontecimento discursivo. É nesse momento que tais palavras se investem de sentido, regulados tanto pela posição em que o sujeito se inscreve quanto pela formação discursiva a que se filia. E, por conseguinte, o sujeito e sentido se constituem.

A produção linguageira de um sujeito resulta "de um efeito de sustentação no já dito que, por sua vez, só funciona quando as vozes se apagam e trazem o sentido para o regime do anonimato e da universalidade. Ilusão de que o sentido nasce ali, não tem história. (ORLANDI, 1996, p. 72)".

Desse silêncio, conforme a autora, que é constitutivo da interpretação, resulta a ilusão, necessária ao sujeito, para que possa experimentar os "seus" sentidos. A isso Orlandi (1996) chama "censura original". Acrescenta que o plágio é um subproduto desse silenciamento e tem particularidades ao se dar no nível da autoria.

Chega-se ao ponto: as produções desse sujeito enunciador, embora ele tenha colocado as referências abaixo de suas participações, são plágios? Há um enunciado no fórum proposto sobre a programação da televisão, e o aluno deve se posicionar. Ao buscar informações sobre o assunto em sites, não há o movimento de interpretação.

Segundo Orlandi (1996, p. 64), 
[...] a interpretação é uma injunção. Face a qualquer objeto simbólico, o sujeito se encontra na necessidade de "dar" sentido. O que é dar sentido? Para o sujeito que fala, é construir sítios de significância (delimitar dominâncias), é tornar possíveis gestos de interpretação.

Considerando isso, o sujeito ao plagiar apaga o seu percurso, a sua identidade, uma vez que não remete o seu dizer ao interdiscurso e retornar sob a forma do intradiscurso. Também há o silenciamento do outro que ele retoma. É uma forma de censura, dado que apaga a voz do outro e a sua, segundo Orlandi (2006, p. 72),

[...] o enunciador que repete e apaga, toma o lugar do autor inevitavelmente, intervém no movimento que faz a história, a trajetória dos sentidos (nega o percurso já feito) e nos processos de identificação (nega a identidade ao outro, e, em consequência, trapaceia com a própria). Estanca assim, o fluir histórico do sentido

A corporalidade apreendida no discurso desse sujeito são principalmente de intelectual, pesquisador, investido de um saber acadêmico. O que se confirma, em relação a sua própria produção, uma vez que denota controle dos mecanismos tanto do processo textual quanto do processo discursivo. Constrói o texto com todos os critérios de coesão e coerência e, principalmente, com a ilusão do fechamento do texto, indispensável à função autor.

\subsection{SUJEITO P4}

Em suas produções no espaço fórum, o sujeito enunciador cria sítios de significação e, assim, historicista o sentido. Em várias passagens de seus textos há palavras usadas que remetem a discursos de outras formações discursivas (regiões do interdiscurso que representam no discurso as formações ideológicas), dos quais derivam os sentidos. São textos construídos com todos os critérios de coesão e coerência, com um fecho, que caracteriza efeito de sentido de acabamento, necessário ao texto.

Há também a inscrição do outro (heterogeneidade mostrada) em seu discurso, o que indicia sua autonomia, por exemplo, em (SQ1) "[...] Concordo com vc, temos que nos ajudar!". É uma forma da modalização autonímica, "a relação entre as 
trocas em diálogo ( $\mathrm{x}$ dito por um/comentário sobre $\mathrm{x}$ enunciado pelo outro) [...] (AUTHIER-REVUZ, 1998, p. 20)".

Em (SQ5) "[...] Minhas meninas também só assistem o que diz respeito à idade delas, elas adoram o Canal Futura (Sítio do Pica-pau Amarelo, Teca na TV, Mundo da Leitura, etc.) [...]"; ao construir a cadeia discursiva, o sujeito depara-se com uma não sequenciação do querer dizer com o que está dito, para que não haja ruptura, o enunciador faz uso dos parênteses. Demarca uma exterioridade que vem marcada para seu discurso.

Os movimentos de contenção da dispersão podem ser vistos, também, ao utilizar os elementos anafóricos, conforme em negrito: "o canal" retoma "A TV Escola", (SQ2) "A TV Escola é um canal do Ministério da Educação, sobre educação e para a educação. No ar 24 horas por dia, o canal exibe os melhores documentários e séries nacionais e internacionais". O uso do "também" para reafirmar o que o outro disse em outro momento: (SQ5) "[...] Minhas meninas também só assistem o que diz respeito à idade delas, elas adoram o Canal Futura (Sítio do Pica-Pau Amarelo, Teca na TV, Mundo da Leitura, etc.) [...]".

Ao construir a cadeia discursiva, o sujeito faz escolhas, essas escolhas que são determinadas, de certo modo, pelo próprio contexto do texto que vai sendo construído. Nas escolhas de algumas, outras são silenciadas. Ainda depara-se com o que Authier-Revuz (2010, p. 261) fala sobre um variado leque "de distorções na adequação da palavra às coisas que ela nomeia".

Por ter esse controle "aparente" sobre o seu dizer, a autoria emerge no texto do sujeito enunciador $\mathrm{P} 4$. O autor é a representação de unidade e delimita-se na prática social como uma função típica do sujeito. Conforme o quadro proposto para análise dos patamares de autoria, já que todo sujeito, a priori, é autor, aponta-se para o nível de autoria 3, ou seja, incluem-se em suas produções: a) organização do texto; b) controle dos mecanismos discursivos; e c) historicização do sentido.

\section{CONSIDERAÇÕES FINAIS}

$O$ sujeito se constitui na e pela linguagem e, ao usar o Ambiente Virtual de Aprendizagem (EVA), uma plataforma de ensino que requer, principalmente, 
o uso da escrita, constitui-se, também, sujeito-autor, dado que é uma função a ser desempenhada pelo sujeito. Como é convocado a desenvolver as atividades propostas no Ambiente de Aprendizagem Virtual, o aluno assume o seu papel social, segundo a forma-sujeito dessa FD. Por conseguinte, ocupa a posição sujeito-aluno, matriculado em um curso de graduação. Ao movimentar-se pela escrita, ao conter a dispersão, no jogo entre estabilização e desestabilização, instaura um novo sentido sobre o sentido, constitui-se sujeito autor. Esse jogo sempre inacabado, incompleto, entre o mesmo e o diferente, confere ao sujeito a ilusão necessária de que ele pode se desprender

[...] do que o ata a si mesmo e aos outros: entre, de um lado, o real da língua, sua relação com as palavras, e de outro, o real da história, em sua experiência de mundo. Determinação da linguagem e da história, o sujeito se inscreve - se escreve - em suas múltiplas versões (ORLANDI, 2004, 118).

Por se tratar de um ambiente virtual de aprendizagem, ou seja, uma "sala de aula virtual", ligado a uma instituição de ensino e, dessa forma, ao discurso pedagógico e/ou discurso da ciência (a esse é o que se pressupõe a instituição vincular-se), o sujeito aí inscrito não pode dizer tudo, há um silenciamento que não é da ordem da produção de sentido que está em qualquer produção de linguagem; há uma interdição do dizer, pela própria posição assumida pelo sujeito, sujeito-aluno. Em relação ao discurso pedagógico, ainda permanece o autoritarismo, em relação ao discurso da ciência, há o cientificismo que regula o dizer. Isso se percebeu na análise das produções dos acadêmicos.

Esse ambiente virtual poderia estar desvinculado desta memória discursiva: a escola como um lugar em que o que se produz, produz para um professor "gerenciador". Essa memória ainda se verificou a partir da análise das produções dos alunos. Mesmo com toda a tecnologia que produz um efeito de "distanciamento" entre professor e aluno, poderiam aí se inscrever outras relações, outros efeitos de sentido e, por isso, haver espaço para que se possa dizer, espaço para a polissemia, desarticulado da posição-aluno, de acordo com a forma-sujeito já cristalizada em nossa sociedade. Menos preso a essa posição e, por conseguinte, à censura que essa posição Ihe confere, de acordo com o discurso pedagógico, o aluno experimentaria outras posições, principalmente a de autor, em níveis mais elevados. A função autor 
está em decorrência do aluno aqui inscrito experimentar práticas de controle dos mecanismos de produção de textos e, também, de como o sentido se produz, para poder desarticular o dado e articular um novo.

Pode-se afirmar então que as posições-sujeito assumidas nesta análise pelos alunos relacionam-se com a mesma forma-sujeito que organiza o domínio de saber (FD), também heterogênea. Conforme Pêcheux (1997, p. 269), essas diversas posições-sujeitos não poderiam ser interpretadas como um "desassujeitamento", em relação à forma-sujeito (a qual assujeita o sujeito), mas formas diferentes do sujeito se subjetivar nessas posições-sujeitos.

Por situar-se em um lugar fora de seu discurso, o sujeito ao torná-lo objeto do seu dizer e, desse lugar (fora do seu discurso), por meio de estratégias linguísticas, metaenunciativas, constitui-se pouco a pouco sujeito-autor, também constitui o texto, dando lugar ao interpretável.

Ao filiar-se a uma determinada formação discursiva, o sujeito, no caso da análise aqui proposta, filia-se à formação discursiva pedagógica, ocupa uma posição e é dessa posição que o que diz faz sentido. O que não o impede de transitar por outras posições-sujeito que o texto em seu processo de construção Ihe possibilita, dado que há ferramentas nesse Espaço Virtual de Aprendizagem para que o sujeito se "mostre" outro. Como se percebeu na análise do corpus, posições-sujeitos: mãe, professor, aluno, aprendiz etc. Não significa dizer que essas posições não se relacionam com a mesma forma-sujeito, que reorganiza o domínio do saber, assim, heterogênea. São formas particulares do sujeito se subjetivar.

O sentido faz sentido porque há um sempre já-lá que retorna para um determinado discurso. Esse repetível da ordem do interdiscurso (o sempre já-lá) ao retornar para o discurso do sujeito, pode ter "deformações", ou seja, deslocamentos. Como no interdiscurso só há potencialidade, "esse repetível" ao atualizar-se em um acontecimento discursivo, inevitavelmente, é outro. E esse outro pode estar no nível do repetível ou do deslizamento, deslocamento. Tais deslocamentos é que apontam para os níveis de autoria, conforme a análise demonstrou. Há uma aproximação entre sujeito-autor no que diz respeito à construção e desconstrução da materialidade linguística, ao organizar o discurso outro, as outras vozes, no sentido de conter o 
movimento de deriva, sob a ilusão de que o texto é uma materialidade plana, homogênea, com um fechamento.

Foi possível perceber, pela análise, também, que conforme 0 distanciamento maior ou menor entre o seu próprio eu (sujeito) e o seu objeto (o texto), ao trazer outros discursos, outras vozes, mostradas ou não, a heterogeneidade constitutiva da própria língua ou a heterogeneidade mostrada, instaura-se níveis ou "graus" de a autoria.

Por se tratar de um ambiente tecnológico, que facilita as pesquisas, alguns alunos trouxeram textos de outros autores, pela tática do "copiar e colar", num movimento de apropriação do discurso do outro, privando o autor de se mostrar e, anulando, em vista disso, o seu próprio percurso no movimento da autoria. Esse sujeito não se coloca na origem do dizer, que faz escolhas e silencia tantas outras, ainda que se saiba que isso é dissimulado pelos esquecimentos $n \div 1$ e $n-2$. Sujeito, então, constituído sócio-historicamente, determinado pelo exterior que retorna para o interior de seu discurso, constituindo-se autor.

A autoria se deu conforme o quadro proposto para parâmetros de análise, ou seja, a autoria se configura em níveis diferenciados, dependendo da inscrição do sujeito na história e, também, ao mover-se em posições-sujeito diferenciadas.

Há de se considerar que a expressão "autor de seus atos" deve ser entendida como o efeito da forma-sujeito, da formação discursiva na qual o sujeito se inscreve, nesta análise, na formação discursiva pedagógica. E, conforme se constatou, a partir da posição ocupada pelo sujeito e de acordo com a formação discursiva que determina o que pode e deve ser dito, os sujeitos materializaram seus discursos conforme proposta já direcionada pelo próprio EVA, pelo próprio professor conteúdista, mas, mesmo assim, sob essa forma-sujeito determinada, houve deslocamentos pela própria tecnologia empregada no ensino a distância, a internet. Abriu-se, em virtude disso, espaço para a polissemia, para o equívoco, para o jogo de negociação entre posições, relações de força.

O aluno por ter acesso ao ensino superior, ou seja, estar matriculado em um curso superior em uma instituição, já demarca a sua inserção na cultura. 0 ambiente virtual como suporte para as interlocuções assegurou-lhe a sua representação como autor. Ao constituir-se sujeito, por identificar-se com a forma- 
sujeito dessa instância, lugar da circulação do discurso da ciência, possibilitou-lhe mostrar-se autor. Ressalta-se, ainda, que cada um dos sujeitos analisados, constituiuse autor, ou seja, mostrou-se autor de acordo com sua inscrição no contexto sóciohistórico, ou seja, em níveis diferenciados.

\section{REFERÊNCIAS}

AUTHIER-REVUZ, Jacqueline. Falta do dizer, dizer da falta: as palavras do silêncio. In ORLANDI, E.P. (Org). [et al]. Gestos de leitura: da história no discurso. 3. ed. Campinas, SP: Editora da Unicamp, 2010.

\section{UNICAMP, 1998.}

Palavras incertas: as não coincidências do dizer. Campinas, SP: Editora da

. Heterogeneidade(s) enunciativa(s). Cadernos de Estudos Linguísticos, Campinas, n. 19, p. 25-42, jul/dez. 1990. (Tradução de Celene M. Cruz e João Wanderley Geraldi)

FOUCAULT. M. A arqueologia do saber. Tradução de Luiz Felipe Baeta Neves. 6. ed. Rio de Janeiro: Forense Universitária, 2002.

O que é um autor? Tradução de Antonio Fernando Cascais e Eduardo Cordeiro. 3. ed. Lisboa: Vega, 1997 (Coleção Passagens).

A ordem do discurso. 3. ed. São Paulo: Loyola, 1996.

FURLANETTO, M. M. Gêneros e autoria: relação, possibilidades e perspectivas de ensino. In: ENCONTRO DO CÍRCULO DE ESTUDOS LINGUÍSTICOS DO SUL, 8., 2008, Porto Alegre - RS. Anais.... Pelotas: EDUCAT, 2008. v. 1.

ORLANDI, Eni Puccinelli. Análise de Discurso. In ORLANDI E.P.; LAGAZZIRODRIGUES S. (Orgs.) Introdução à ciências da linguagem - discurso e textualidade. Campinas, SP: Pontes Editores, 2006.

Cidade dos sentidos. Campinas, SP: Pontes, 2004.

. Análise de discurso: Princípios e procedimentos. Campinas, SP: Pontes, 1999.

. Discurso e leitura. Campinas, SP: Editora da UNICAMP, 1988.

Interpretação: autoria, leitura e efeitos do trabalho simbólico. Petrópolis:

Vozes, 1996. 
PÊCHEUX, Michel. Papel da memória. In ACHARD, Pierre et al. Papel da memória. Tradução de José Horta Nunes. 3 ed. Campinas, SP: Pontes Editores, 2010. p. 4957.

Semântica e discurso: uma crítica à afirmação do óbvio. Tradução de Eni P. Orlandi [et al.]. 3. ed. Campinas, SP: Editora da UNICAMP, 1997.

\section{ANEXO}

\section{P 1 (18/09/2009 11:57)}

\section{Título: Necessidade de controle}

Oi, xxx, concordo com sua posição no que tange quanto a TV possuir grande força, como agente transmissor de cultura e boa informação, mas também precisa de controle e seleção, para que filtremos as coisas positivas e não deixemos nossos filhos à mercê de tanta negatividade e péssimos exemplos.

\section{P1 (18/09/2009 12:01)}

Título: Mudanças necessárias

XXX, creio que você chegou a uma conclusão muito prática neste fórum, quando sugere que deveria haver uma via de comunicação para que todos os telespectadores interessados emitissem sua opinião sobre a TV que queremos. Você foi a única a mencionar esta ação concreta, meus parabéns pelo seu raciocínio prático e conectado com nossa época. [...]

\section{P1 (18/09/2009 12:04)}

\section{Título: Responsabilidade Compartilhada}

Olá, xxx. Parabéns pela lucidez de seu comentário. Você foi muito eficaz na avaliação crítica de que a responsabilidade pela Tv que temos a disposição, é fruto de nossa responsabilidade/passividade enquanto espectadores. Temos nossa parcela nessa relação bilateral, que não estamos cumprindo por comodismo.

\section{P1 (10/09/2009 19:32)}

Título: Que tal nos 'ligarmos" em quem amamos?

Imagine qualquer dia da semana, de qualquer mês, de qualquer estação do ano, de qualquer ano... [...] Pense em um objeto que está em mais de um cômodo de sua casa, como protagonista dos diálogos, dos temas a serem conversados, dos sentimentos a serem 


\section{CRIAR EDUCAÇÃO}

Revista do Programa de Pós-Graduação em Educação - UNESC

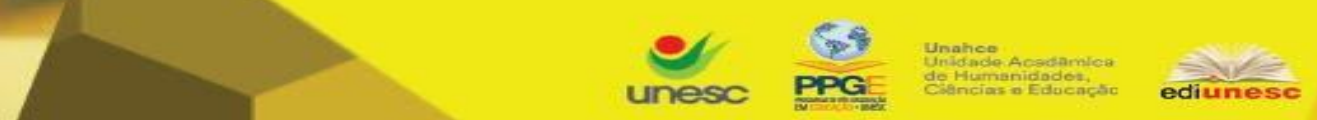

vivenciados... Esse objeto falante, colorido, expressivamente alvo de atenção, é a TV. Sim, a TV nossa de cada dia e de todos os dias... Você já parou para refletir quanto tempo você e sua família passam diante da TV? [...]

\section{P1 (10/09/2009 17:27)}

Título: TV e ansiedade

Oi, P6, você está com razão ao apontar os aspectos positivos e negativos da TV. Concordo com todos os argumentos e "coloquei o chapéu" quando você disse que tem pessoas que fazem as refeições diante da TV. Eu sou uma dessas... Tenho filho pequeno e meu dia é uma loucura, então, quando há um tempinho de ver um programa que gosto, uno as duas coisas, embora saiba que não é saudável...

P 2 (06/09/2009 22:08)

Título: A droga da tv

A violência e o sensacionalismo exibidos pela tv são comparados ao uso de drogas, existe a necessidade da adequação das doses para a obtenção do efeito desejado. A grande questão encontra-se no processo de desintoxicação, que no caso das drogas, com persistência, é possível, e no caso da tv?

\section{P 3 (08/09/2009 07:39) (cópia feita pelo P3)}

Título: Crianças e a Televisão

É uma questão de grave preocupação que a televisão tem invadido de maneira ruim as nossas salas-de-estar. As crianças são as mais afetadas. A preocupação sobre os efeitos da televisão sobre as crianças tem centrado exclusivamente sobre o conteúdo dos programas que elas vêem. [...] Crianças e a Televisão, neste endereço: "http://www.shvoong.com/Autor dhawanbm.

\section{P4 (18/09/2009 16:51)}

Título: Obrigada!

Concordo com vc, temos que nos ajudar!

\section{P4 (10/09/2009 16:37)}

Título: Obrigada, pela dica

Oi xxx, assisti ao documentário, e é mesmo nossas crianças estão influenciadas pelas propagandas, querendo consumir tudo o vê sem precisar, temos que consumir somente o que 
precisamos, sem exageros. Minhas meninas também só assistem o que diz respeito à idade delas, elas adoram o Canal Futura (Sítio do Picapau Amarelo, Teca na TV, Mundo da Leitura, etc.) e ainda tem limite na frente da tv, na minha casa, ninguém assisti a novelas e outros lixos, se a programação estiver ruim, desligo a TV, até para os jornais.

Recebido em março 2019 Aprovado em março 2019 